\title{
Compact Planar 3-Way Power Divider Using Left- Handed Transmission Lines
}

\author{
K. W. Eccleston \\ Dept of Electrical and Computer Engineering, \\ University of Canterbury, Christchurch, NEW ZEALAND \\ Email: kim.eccleston@elec.canterbury.ac.nz
}

\begin{abstract}
In this paper, we propose a three-way planar fork power divider that has its ports located on a straight line. To achieve equal phase output ports, transmission lines are inserted between the fork divider and two of the output ports. To reduce circuit size without the need for meandering, left-handed transmission lines are also used. Simulations of a 3-way microstripline power divider operating at $5 \mathrm{GHz}$ demonstrated that the performance was comparable to a 3-way divider realized from only microstripline, but with a size reduction of $27 \%$.
\end{abstract}

\section{INTRODUCTION}

A pair of power dividers can be used to combine several power amplifiers in parallel thereby achieving higher output power than a single amplifier module. For this to work effectively, the amplifier modules must be identical and the power dividers must achieve equal power division with equal phase. For practical implementation of a parallel combined power amplifier in microstripline, the power dividers need to have output ports aligned in a straight line.

Commonly used power dividers that are suitable for realization in microstripline are planar and include sectorial [1] and fork dividers. The problem with planar microstripline dividers is that equal-phase output ports are normally located on an arc. Further, layout requirements, such as amplifier module width, may dictate a minimum separation between output ports.

In this paper we consider a 3-way divider that is based upon an internal 3-way fork divider comprising three $90^{\circ}$ microstriplines with characteristic impedance $Z_{\mathrm{OT}}$ equal to $Z_{\mathrm{o}} \sqrt{3}$ where $Z_{\mathrm{o}}$ is the port reference impedance This value of $Z_{\mathrm{oT}}$ ensures that the input port is matched to $Z_{\mathrm{o}}$ at the centre frequency. To locate the output ports on a straight line, extra microstriplines with characteristic impedance $Z_{\mathrm{o}}$ can be used to connect the internal divider output ports to the external ports as shown in Fig. 1(a) and Fig. 1(b).

To realize the 3-way divider depicted in Fig. 1(a), where all the microstriplines feeding the output ports have equal length (d), meandering of the microstripline feeding port 3 is required [2]. However, the area occupied by the meandered microstripline further increases the size of the divider. For the 3-way divider depicted in Fig. 1(b), d needs to be integer multiples of one-wavelength and clearly circuit size increases unless slow-wave structures [3][4] or meandering are applied to the microstriplines feeding ports 2 and 4 . This approach however obviates the need for the extra microstripline feeding port 3.

\section{PROPOSED 3-WAY DIVIDER}

Compact transmission lines can be artificially realized with lumped elements and comprise a periodic cascade of unit cells. The length of the unit cell and hence the overall transmission structure length is determined by the length of the series element(s) of the unit cell. In general, thin film capacitors are more compact compared with inductors and hence a high-pass unit cell is expected to be shorter in length than a low-pass unit cell that are commonly employed in artificial transmission lines [4]. Periodic structures with high-pass unit cells have been previously used in rat-race couplers [5] and amplifiers [6] to reduce circuit size and / or increase bandwidth and have been dubbed left-handed transmission lines (LHTLs) [5].

The approach in this work is to employ LHTLs in place of lengths of microstriplines to reduce overall circuit size as shown in Fig. 1(c). In principle, the 3-way divider operates similarly to that in Fig. 1(b). This means that the total insertion phase of the LHTL, and the microstripline of length $d$, is integer multiples of $360^{\circ}$.

Ideally, a LHTL unit cell comprises a shunt inductance $\left(\mathrm{L}_{\mathrm{p}}\right)$ and series capacitance $C_{S}$ as shown in Fig. 2(a) and [5][6]. However, the parasitic series inductance of the capacitor can be significant leading to the equivalent circuit of the LHTL the unit cell shown in Fig. 2(b). It can be shown that the insertion phase $\left(\angle \mathrm{S}_{21}\right)$ in the pass-band of the LHTL unit-cell equivalent circuit (Fig. 2(b)) is given by:

$$
\varphi=\arctan \frac{\omega\left(\frac{\mathrm{L}_{\mathrm{p}}\left(1-\omega^{2} \mathrm{~L}_{\mathrm{s}} \mathrm{C}_{\mathrm{S}}\right)}{\mathrm{Z}_{\mathrm{o}}}+\mathrm{C}_{\mathrm{S}} \mathrm{Z}_{\mathrm{o}}\right)}{\omega^{2} \mathrm{~L}_{\mathrm{p}} \mathrm{C}_{\mathrm{S}}\left(1+\frac{\mathrm{L}_{\mathrm{S}}+\mathrm{L}_{\mathrm{p}}}{\mathrm{L}_{\mathrm{p}}}\right)-1}
$$

where $L_{S}$ is the parasitic inductance of the capacitor, $Z_{o}$ is the system reference impedance.

An integer number ( $n$ ) of unit cells is cascaded to give the required phase of the LHTL. Let us assume for the moment that the effect of $\mathrm{L}_{\mathrm{S}}$ is insignificant. For small values of $\varphi$ (less than $30^{\circ}$ ) the unit cell behaves as a short length of transmission line with electrical length $-\varphi$, and the total phase shift of the $n$ cell LHTL will be $n \varphi[5][6]$. 
(a)

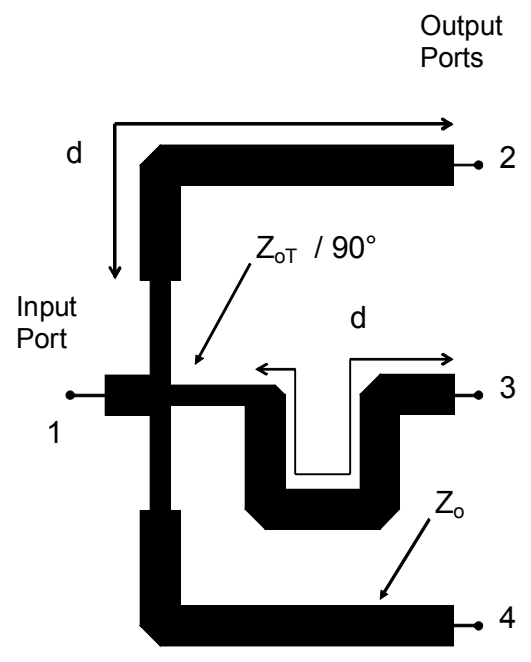

(b)

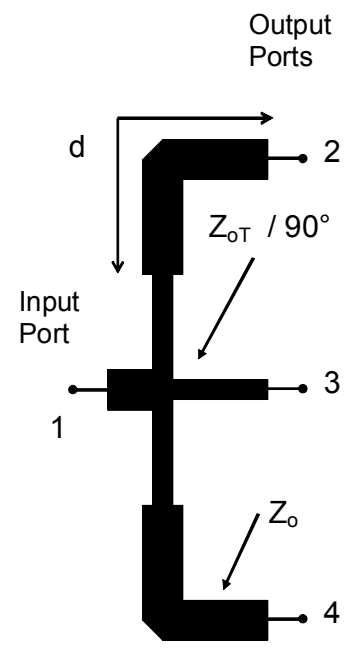

(c)

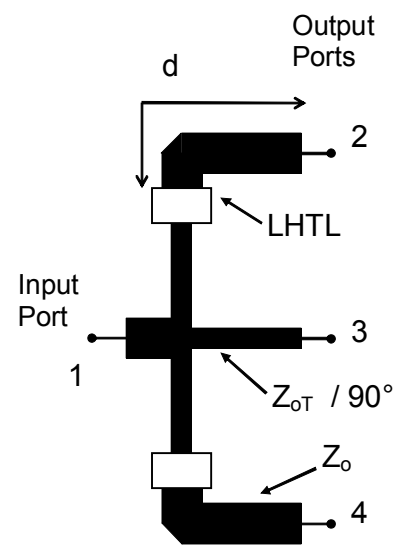

Fig. 1 Three-way fork divider with output ports located on a straight line: (a), (b) using only microstripline, and (c) proposed structure using both microstripline and LHTLs.
However, a small value of $\varphi$ requires large values of $L_{p}$ and $C_{S}$ and a large value of $\mathrm{n}$ to achieve a given total insertion phase $n \varphi$. Hence the LHTL will be lengthy as a result of large $C_{S}$ and $\mathrm{n}$ and therefore will not offer a space saving advantage. Although a lower number of unit cells yields a smaller structure (due to low $\mathrm{n}$ and low $\mathrm{C}_{\mathrm{S}}$ ), $\varphi$ will need to be higher to compensate for a lower $\mathrm{n}$ to achieve the same total insertion phase $n \varphi$. This will mean that the unit-cell will be mismatched to a real impedance and the equivalent short-length transmission line approximation is less accurate. Therefore the approach taken in this work is to design the LHTL so that it is essentially a half-wave transformer at the centre frequency and therefore achieves perfect match at the centre frequency. The bandwidth over which good input match is obtained will increase when the characteristic impedance of the LHTL is near the system reference impedance $Z_{0}$.

(a)

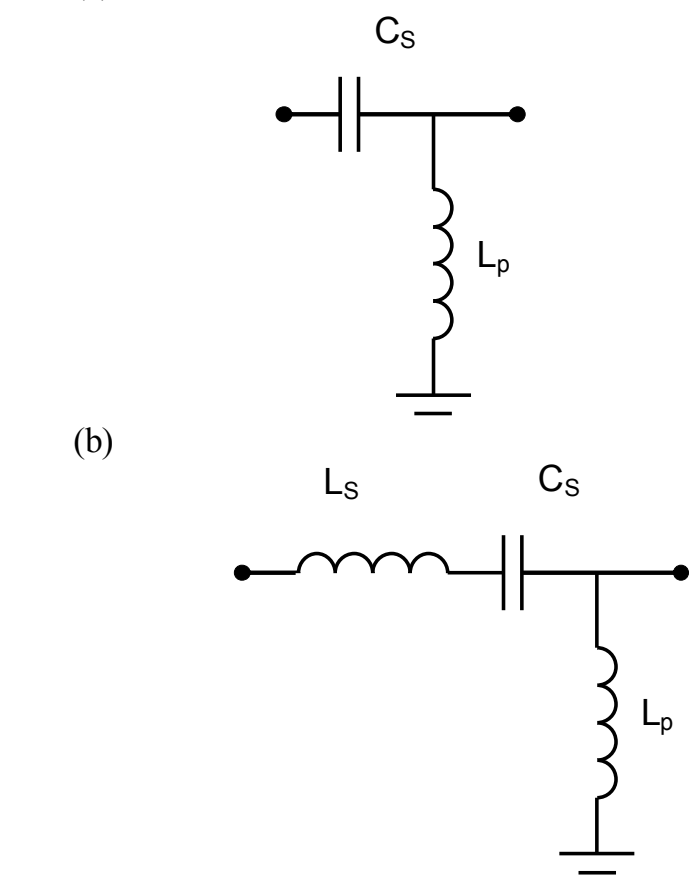

Fig. 2 Unit-cell for LHTL transmission structure: (a) ideal, and (b) equivalent circuit that includes capacitor parasitic inductance.

\section{DESIGN OF THE LHTL}

We consider the design of a 3-way power divider operating at $5 \mathrm{GHz}$ and realized on a substrate of height $0.7874 \mathrm{~mm}$ and dielectric constant of 2.22. The value of $\mathrm{C}_{\mathrm{S}}$ was chosen to be 1 $\mathrm{pF}$ and to be obtained using ATC600 $\mathrm{S}^{1}$ ceramic chip capacitors, which have a series parasitic inductance $\left(\mathrm{L}_{\mathrm{S}}\right)$ of $0.254 \mathrm{nH}$. Using (1), $\mathrm{L}_{\mathrm{p}}=1.54 \mathrm{nH}$ gives an insertion phase of $45^{\circ}$ at 5 $\mathrm{GHz}$. Hence four such unit cells of the type indicated in Fig. 2(b) are expected to give an insertion phase of approximately

\footnotetext{
${ }^{1}$ American Technical Ceramics: www.atceramics.com
} 
$180^{\circ}$ at $5 \mathrm{GHz}$. Since the unit cells depart from transmission line behavior somewhat, it was necessary to adjust $\mathrm{L}_{\mathrm{p}}$ to 1.31 $\mathrm{nH}$ so that the 4-cell LHTL behaves as a half-wave transformer at $5 \mathrm{GHz}$. The inductors can be realized with short-circuit stubs and due to the small size of the capacitors, they are in close proximity to each other as shown in Fig. 3.

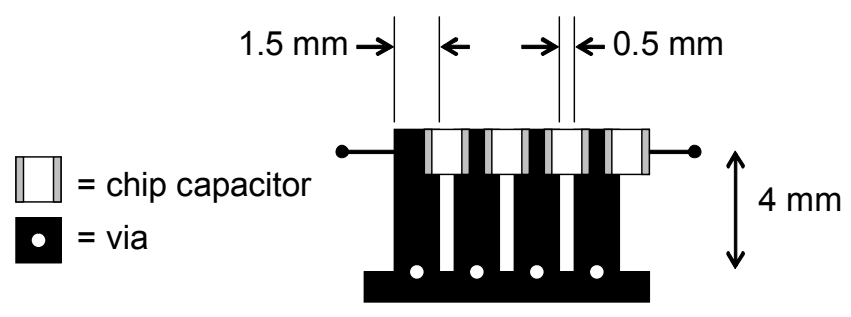

Fig. 3 Layout of 4-cell LHTL. Substrate: height $=31$ mil and $\varepsilon_{\mathrm{r}}=2.22$.

Simulations and fine tuning of the LHTL were performed using commercial microwave circuit simulation software and accounted for coupling between stubs and short-circuit vias. The important dimensions of the resulting structure are shown in Fig. 3. The calculated response is shown in Fig. 4. At 5 $\mathrm{GHz}, \mathrm{S}_{11}$ is minimum at $-18.7 \mathrm{~dB}$, and $\mathrm{S}_{21}$ has a phase of $155^{\circ}$. This means that the required insertion phase of the microstripline of length d needs to be $-155^{\circ}$, or in other words an electrical length of $155^{\circ}$. The length of the LHTL structure is $8.5 \mathrm{~mm}$ and this is to be compared with about $19 \mathrm{~mm}$ for a microstripline with the same electrical length at $5 \mathrm{GHz}$.

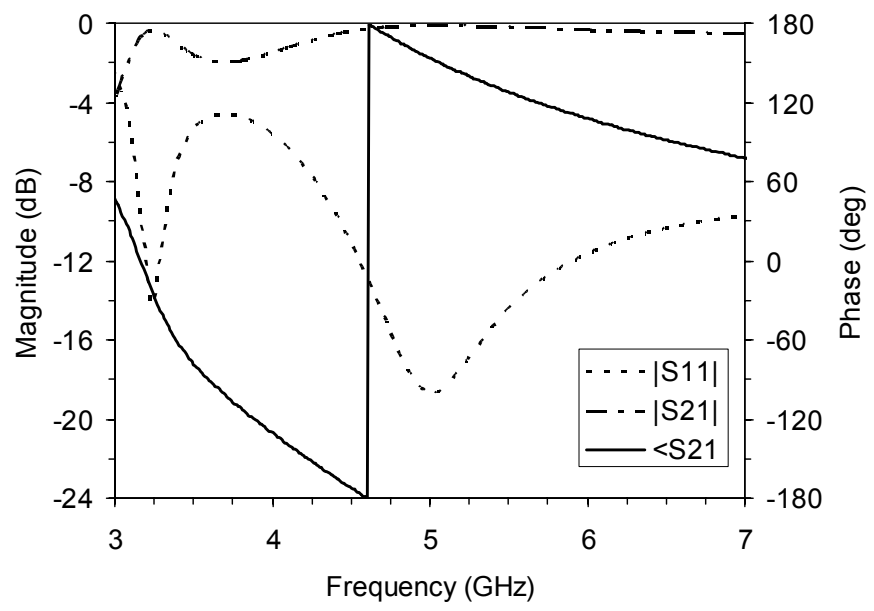

Fig. 4 Simulation results for the 4-cell LHTL.

\section{DESIGN OF THE DIVIDER}

Two 3-way dividers were then designed: (i) of the type shown in Fig. 1(b), and (ii) of the proposed type (Fig. 1(c)). The first type is used for comparison with of the proposed type. In both cases, $Z_{\text {оT }}$ was set $87 \Omega$ for operation in a $50 \Omega$ system $\left(Z_{\mathrm{o}}\right)$. The electrical lengths $(\mathrm{d})$ of the microstripline feeding ports 2 and 4 were chosen to be the minimum length to achieve an electrical length of $360^{\circ}$ for the divider shown in Fig. 1(b) and $155^{\circ}$ for the proposed divider (Fig. 1(c)).
The two dividers were simulated using Sonnet ${ }^{2}$. Sonnet performs full-wave electromagnetic (EM) analysis of planar circuits. In the case of the proposed type of divider, the LHTL was represented by a 2-port element for which its S-parameters were calculated using the commercial microwave circuit simulation software. The most relevant results of the simulations (input reflection coefficient, and forward transmissions) are shown in Fig. 5. Since the dividers are symmetrical, $\mathrm{S}_{41}$ is not displayed. It can be seen both provide in-phase equal power division at $5 \mathrm{GHz}$. The bandwidth for which the output phase difference $\left(\angle \mathrm{S}_{21} / \mathrm{S}_{31}\right)$ is less than $45^{\circ}$ is $0.805 \mathrm{GHz}$ for the proposed divider and $1.23 \mathrm{GHz}$ for the divider shown in Fig. 1(b). Over this bandwidth, both dividers have excellent input port match $\left(\left|\mathrm{S}_{11}\right|\right)$; and the output levels differ by up to $1.9 \mathrm{~dB}$ for the proposed divider and up to $1 \mathrm{~dB}$ for the divider shown in Fig. 1(b).

(a)

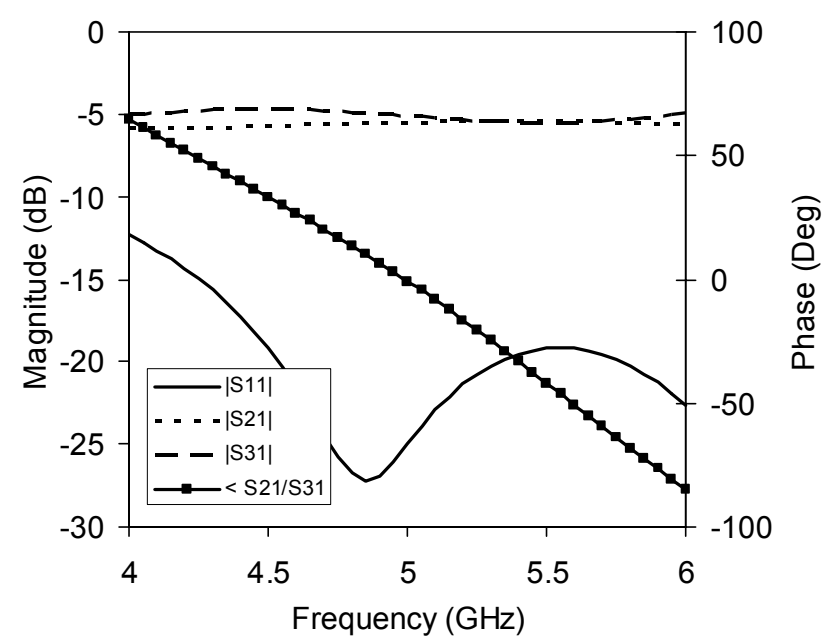

(b)

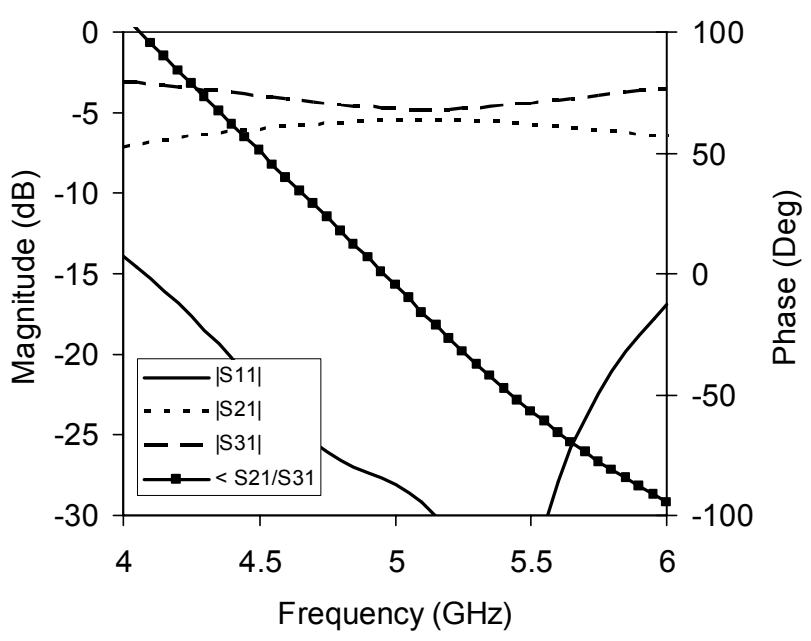

Fig. 5 Simulation results $\left(\left|\mathrm{S}_{11}\right|,\left|\mathrm{S}_{21}\right|,\left|\mathrm{S}_{31}\right|\right.$ and $\left.\angle \mathrm{S}_{21} / \mathrm{S}_{31}\right)$ for: (a) divider of type Fig. 1(b), and (b) the proposed divider incorporating the LHTL Fig. 1(c).

\footnotetext{
${ }^{2}$ Sonnet is trademark of Sonnet Software Inc: www.sonnetusa.com
} 
The size of the proposed divider is $24 \mathrm{~mm} \times 80 \mathrm{~mm}$ and the output port separation is $33.3 \mathrm{~mm}$, whilst the size of the divider shown in Fig. 1(b) is $24 \mathrm{~mm} \times 110 \mathrm{~mm}$ and the output port separation is $45.4 \mathrm{~mm}$. Hence the use of the LHTLs results in saving of $27 \%$ area.

\section{CONCLuSiON}

In this paper we have shown the design of 3-way microstripline power divider that employs left-handed transmission structures achieve size reduction compared to a 3-way divider realized with only microstriplines. The left-handed transmission structure employs lumped elements and is designed to account for the parasitic inductance of the capacitors, and cross-talk between inductors. Design considerations dealt with the compromise that needs to be made between the performance and size of the LHTL. The simulation results of a divider operating at $5 \mathrm{GHz}$ demonstrate the feasibility of the approach when compared to a 3-way divider realized from only microstriplines.

\section{REFERENCES}

[1] M. D. Abouzahra and K.C. Gupta, "Multiport Power Divider-Combiner Circuits Using Circular-Sector-Shaped Planar Components", IEEE Transactions on Microwave Theory and Techniques Vol. 36, No.12, pp 1747-1751, Dec. 1988.
[2] H. Kobeissi and $\mathrm{K} . \mathrm{Wu}$, "Design Technique and Performance Assessment of New Multiport Multihole Power Divider Suitable for M(H)MIC's", IEEE Transactions on Microwave Theory and Techniques, Vol. 47, No. 4, pp 499 - 505, April 1999.

[3] C. O. Lee and C. C. Shin, "Enhanced periodic structures with compact size", Electronics Letters, Vol. 40, No. 8, pp 479- 481, 15 April 2004.

[4] K. W. Eccleston and H. M. Ong, "Compact Planar Microstripline Branch-Line and Rat-Race Couplers", IEEE Trans. on Microwave Theory and Techniques, Vol. 51, No. 10, pp 2119-2125, October 2003.

[5] H. Okabe, C. Caloz, and T. Itoh, A compact enhancedbandwidth hybrid ring using a left-handed transmissionline section, 2003 IEEE MTT-S International Microwave Symposium, pp 329-332.

[6] K. W. Eccleston, “Application of Left-Handed Media in Distributed Amplifiers", Microwave and Optical Technology Letters, Vol. 44, No. 6, pp 527 - 529, 20 March 2005. 